Journal of Sustainable Development of Transport and Logistics

journal home page: https://jsdtl.sciview.net

Luzhanska, N. (2020). Impact of the cargo customs complex efficiency on the supply chain reliability. Journal of Sustainable Development of Transport and Logistics, 5(1), 96-102. doi:10.14254/jsdtl.2020.5-1.9.

\title{
Impact of the cargo customs complex efficiency on the supply chain reliability
}

\section{Nataliia Luzhanska}

Transport and Informational Technologies Faculty, Department of International Transportation and Customs Control, National Transport University,

1, Mykhaila Omelianovycha - Pavlenka Str., Kyiv 01010, Ukraine

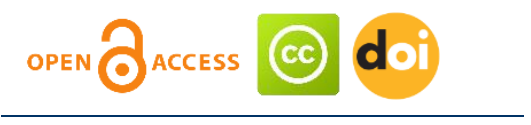

\section{Article history:}

Received: January 15, 2020

1st Revision: February 25,

2020

Accepted: April 09, 2020

\section{DOI:}

10.14254/jsdtl.2020.5-1.9

\begin{abstract}
Creating supply chain involving the customs infrastructure facilities is an urgent topic when shipping cargo internationally. The most in demand are cargo customs complexes, which have in their structure customs storerooms, warehouses of temporary storage, perform freight-forwarding, and customs-brokerage and other functions that are necessary to perform foreign economic activity. Also there are subdivisions of customs authorities on their territory. This type of business activity provides the business entities with the comprehensive service and enables them to reduce the time spent moving to each of the necessary control services or logistics facilities when moving cargoes in different customs regimes. Therefore, it is proposed to apply the concept of logistics chain reliability with a freight customs complex as its element. The latter will take into account business entities' financial and time expenditures with non-productive timing at the different transition stages of material flow, and will enable to optimize information flows. The paper considers the procedure of placing imported goods in a temporary storage warehouse. It is proposed the regulation methodology for individual service stages provided by a freight customs complex. The generalized algorithm for constructing a reliability model of a freight customs complex`s operation is offered allowing to determine the reliability level of each individual element in a logistics chain.
\end{abstract}

Keywords: custom infrastructure, temporary storage warehouse, supply chain, custom clearance, logistics, costs, cargo custom complex, reliability. 


\section{Introduction}

Cargo customs complexes are located throughout the country, have different levels of technical, technological and organizational support, as well as the capacity that is limited by the available space to enter its territory to be served or the possibility to store goods in the required volumes and for a specified time. Therefore, when designing a logistics chain involving a cargo customs complex, these aspects must be taken into account in order to avoid service queues or service denials altogether. Waiting time for service or arranging additional terms of cooperation will adversely affect the efficiency of the logistics chain and lead to losses and disruption of delivery timeframes, as these aspects are not subject to regulation and forecasting.

The relevance of this topic is the effective planning and management of supply chains, taking into account financial losses that can be caused by unplanned downtime or unproductive use of time in performing foreign economic activities. These time losses can be caused by the lack of business entities' professional approach, which are links in the logistics chain in their duties under the terms of the service contract, queues for customs clearance at internal customs and when crossing the state border. Therefore, it is necessary to determine the reliability of the logistics chain, which will be in compliance with the delivery time, to ensure the safety of cargo and to prevent the additional costs of the parties to the foreign trade contract due to unprofessional or illegal actions of third parties.

Nowadays, minimizing the number of links in the logistics chain by broadening the range of services provided by them is the most appropriate for all participants of foreign economic activity. This implementation will help to improve the coherence of all participants' actions and achieve optimization in managing material, financial, information and service flows, and therefore, will lead to increased reliability of delivery. Thus, the main purpose of this study is to optimize logistics processes and customs formalities performance.

One of the solutions is to involve cargo custom complexes when creating logistics chain. Therefore, the paper proposes to investigate the possible additional time losses that may occur when there is a service queue or denial of service, and to establish financial costs in connection therewith.

\section{Literature review}

In its infancy the supply chain was considered only at the level of production, later the need arose for a more detailed study of this issue by taking into account the performance indicators of all involved participants in the delivery of goods from producer to consumer. Unlike the classic definition (Rodnikov, 2000), in the papers of Gadzhinskiy, A., Christopher, M., Mirotin, L., Waters, D., (Gadzhinskiy, 1999; Christopher, 2004; Mirotin \& Sergeev, 2000; Waters, 2003). This term has acquired an economic nature, not a technological one, and characterizes the efficiency of promoting material flow. With the development and establishment of market relations in logistics activities, the concept of an integrated logistics chain has been created (Khendfild \& Nikols, 2003; Pustynnikova, 2016).

A significant number of scientists dealing with various aspects of their organization, planning and management deal with questions of the effectiveness of supply chain functioning (Stock \& Lambert, 2005; Pirttila et al., 2020; Jiang et al., 2018).

The paper (Wang et al., 2019) highlights three supply chain resources: flows related to information, logistics and finance. Their interplay has critical for the development of supply chain service capabilities, which in turn lead to an improvement in the quality of supply chain relationships that assessed by the dimensions of trust improvement / commitment, risk mitigation, and customer satisfaction.

Measure the reliability of a supply chain is an important step to promote the construction of more resilient chains. The resilience is necessary to guaranty the efficient and secure global movement of goods. The paper (Solano A.B. et al., 2016) proposes an instrument to analysis and evaluates the reliability of a system. Also compare scenarios of reliability between a basic supply chains versus complex systems. Finally present useful conclusion to the construction of resilient and robust supply chain.

However, today, the effectiveness of the supply chains is significantly influenced by customs authorities, whose activities are associated with significant loss of time during customs clearance and 
crossing the state border (Volpe Martincus et al., 2015). Hence, from a commercial point of view, any delays automatically turn into a cash equivalent (Krikavsky, 2004; Elliott \& Bonsignori, 2019; Biljan \& Trajkov, 2012).

Therefore, it is urgent to reduce the time spent in customs paperwork by studying the technological processes of material flows at customs infrastructure facilities.

The paper (Pourakbar et al., 2018) proposes a model that allows customs to optimize its inspection process to target high-risk containers without hindering the flow of safe containers with extra delays at ports. The model characterizes optimal informational and physical inspection rates as a function of the risk factors attributed to containers. This model is used to analyze how an effective public-private partnership for risk and security management can be established between customs and private firms.

This result can be achieved through the application of the electronic document flow when completing customs formalities, as well as a reduction in the number of business entities constituting a logistics chain due to comprehensive services provided by customs and logistics infrastructure facilities.

The usage of e-Customs platforms ensures a more cost-efficient application of resources while preserving a smooth flow of goods across international borders (Urciuoli et al., 2013). However, the lack of stability forces the users of the European e-Customs to continuously modify and investment in IT participate in the infrastructure (Henningsson et al., 2011). The paper of Raus, M., Flugge, B., Boutellier, R. (Raus et al., 2009) investigates the diffusion of an e-Government innovation, a common eCustoms standardized solution. To achieve trade facilitation as well as to secure import and export the European Government aims to have a common e-Customs standardized solution. To simplify customs clearance of vessels and cargoes the Mednet project was launched (Morales-Fusco et al., 2016). As part of the project a common evaluation framework for the performance of ports in the form of a set of Key Performance Indicators (KPIs) together with a list of the best practices in terms of operations and customs procedures was developed.

\section{Methodology and results}

Supply chain management aims to minimize overall logistics costs while meeting the existing level of demand for services. Even a minor disruption in the supply chain leads to increased logistics costs. The stability and constancy of the logistics chain is determined by the aggregated conditions of all its elements and connections, which are estimated by reliability. Any part of the supply chain affects each of these parameters, reducing the reliability of the contract terms implementation.

Reliability is one of the most important aspects of logistics efficiency. The high degree of uncertainty includes the use of various strategies by logistics operators that involve significant costs. Reliability of supply and cost of logistics significantly affect the competitiveness of the enterprise. The reliability of the supply chain is important not only as a factor determining the costs and actual delivery time of cargo, but also as a factor determining the level of logistics service of the providing it company.

One of the most important criteria of the supply chain reliability is cargo delivery within the specified time-frame. On the second place is the accuracy of freight shipment and the documents registration clearance.

Today, the market of Ukraine is developing a situation that requires urgent measures to increase the reliability of supply chains in order to ensure the competitiveness of enterprises not only in domestic but also in international markets. The main action facilitating the solution of this situation in the shortest time is the integration of the participants of the logistics chain to ensure the overall economic effect and to create the competitiveness of a certain enterprise in terms of the logistics service level. A higher level of reliability will improve the accuracy of orders. Increasing reliability of supplies will allow to improve attractiveness of domestic exports due to timely delivery to foreign customers, and also will ensure uninterrupted supply of imported goods to the Ukrainian market. The foreign trade cargo delivery time provision is formed by minimizing unproductive time expenses at all stages of delivery during the technological operations performance, customs formalities and documentary support preparation for the transportation. 
The impact of reliability of the infrastructure facilities on the economic indicators of their functioning is diverse: on the one hand, increasing the reliability of customs and logistics services leads to an increase in the operation costs $-C_{E}$, as well as design and construction, equipping with technical means, etc., and on the other - to reduce losses due to the violation of the terms of goods delivery $-C_{\Pi}$.

In more detail, we will look at the process of placing imported goods into the temporary storage warehouse, which is located on the territory of the cargo customs complex, taking into account delays or denial of service, which will affect the total duration of delivery.

The following procedure is used to place the cargo in the temporary storage warehouse: signing a service agreement; cargo customs complex services payment; arrival of a vehicle; obtaining a vehicle entry pass; weight control of a vehicle at arrival on the territory of the cargo customs complex; delivery confirmation; preparation of documents from the importer with the request to place the cargo in the temporary storage warehouse; receiving customs authority's approval to place cargo in the temporary storage warehouse; placing cargo in the warehouse; customs authority`s stamps on documents; leaving the cargo customs complex.

In such a situation, it is advisable to normalize the reliability of individual stages of service at customs cargo complexes. The solution to this problem will determine the shortcomings in the operation of the customs infrastructure object, as well as take measures to eliminate them. Reliability can be normalized on the basis that the integral function $C_{0(P)}$, which includes the operation costs of the cargo customs complex, that is, maintaining a given level of reliability and costs arising from an insufficient level of reliability should reach a minimum:

$$
C_{0(P)}=C_{E(P)}+C_{\Pi(P)}
$$

Supposedly there is an optimal level of reliability with minimal operation total costs for the cargo customs complex and costs for disruption in customs and logistics services.

The initial data necessary to solve the problem of constructing a model of reliability of the cargo customs complex must contain the following information.

1. The resulting list of all disruption and failures occurring at the cargo customs complex for a certain period of time, indicating the amount of expenses incurred.

Then the algorithm for creating a model of reliability of customs and logistics services is described by the following sequence of actions:

1. Investigation of a typical sequence of events occurring at cargo customs complexes. The number of key events that stand out during the study will depend on the complexity of the system and the requirements for model accuracy.

2. Consideration of each particular event from the standpoint of the probability of disruption in the event under investigation, that is, the occurrence of the event and the likelihood of expenses due to disruption. These two values can be determined from the accumulated statistics in various ways.

3. Consolidation of the resulting structure. Of course, the selection of several complex events, those correspond to the main stages of the studied processes.

4. Determining the magnitude of costs arising from disruptions in highlighted complex events $E_{1}$. It is advisable to determine these values taking into account the probability of each occurring event $e_{1}$, that is part of the event $E_{1}$.

5. Disruptions impact analysis on the amount of possible costs. For example, if the structural scheme of the cargo customs complex is depicted as a consistent combination of the elements, the disruption in any of the considered events will lead to a destruction of the of the whole system operation, and accordingly to an increase in costs.

6. An objective function creation, as a dependence between the probability levels of each complex event occurrence and the level of possible costs.

7. Application of additional restrictions. Restrictions may vary.

Based on the foregoing, the task can be written as follows: 


$$
\left\{\begin{array}{l}
X\left(p_{1}, \ldots, p_{n}\right) \geq P_{o} \\
F\left(p_{1}, \ldots, p_{n}\right)=C\left(p_{1}, \ldots, p_{n}\right)+W\left(p_{1}, \ldots, p_{n}\right) \rightarrow \min \\
p_{i} \leq P_{i}^{\max }
\end{array}\right.
$$

where $p_{1}, \ldots, p_{n}$ - the likelihood of an event $E_{1}, \ldots, E_{n}$;

$C\left(p_{1}, \ldots, p_{n}\right)$ - total expenses due to disruption in the occurrence of events $E_{1}, \ldots, E_{n}$;

$W\left(p_{1}, \ldots, p_{n}\right)$ - total costs required to ensure a specified level of reliability;

$P_{i}^{\max }$ - the highest possible probability of events $E_{1}, \ldots, E_{n}$;

$X\left(p_{1}, \ldots, p_{n}\right)$ - system reliability function;

$P_{o}-\mathrm{t}$ he required level of system reliability.

8. Determination of the necessary values $p_{1}, . p_{2}, . ., p_{n}$. To do this, the mathematical methods can be used and the system (2) could be rewrite as follows:

$$
\left\{\begin{array}{l}
X\left(p_{1}, \ldots, p_{n}\right) \geq P_{o} \\
\frac{\partial F\left(p_{1}, \ldots, p_{n}\right)}{\partial p_{i}}=0 \\
p_{i} \leq P_{i}^{\max }
\end{array}\right.
$$

Let us consider an example of a reliability model formation for a cargo customs complex operation on the basis of the given generalized algorithm.

A typical sequence of actions at a cargo customs complex when providing customs and logistics services depends on a number of factors, the main one of which is the function of the facility of the customs infrastructure in the handling of cargo flows under certain customs regimes.

From the point of view of reliability, at each of the considered links in the logistic process, a number of events can be distinguished that will affect the overall reliability of service at the cargo customs complex as a whole. Since an enlarged system is considered, each selected element is a subsystem with its own structure.

Several events $e_{1}$, which will cause costs $c_{1}$, will be described. On arrival of the vehicle at the cargo customs complex, two events may occur that can be regarded as a destruction in the system functioning. The first of them is associated with the waiting queue of vehicles and therefore to unproductive time losses. It is determined by the intensity of the applications flow, the cargo customs capacity and is characterized by the probability of the event occurrence.

The second event occurs when there is no room at the temporary storage warehouse for placing the arrived cargo and is determined by the balance between the input material flow and the warehouse capacity. Thus, the damage is the sum of the lost profit from storage of goods at the customs infrastructure and the additional costs of transporting goods to another temporary storage warehouse for the consignee.

The probability is that at some point $T_{H}$ there will be a queue in front of the cargo customs complex, equal to $p_{1}^{1}$ and the amount of possible damage is proportional to the downtime. To simplify, we take this value constant and equal $c_{1}^{1}$. Such values as probability of having a waiting que and downtime could be calculated using the theory of queuing theory.

Probability that at time $T_{H}$ the warehouse will be full (or not able to accommodate the entire volume of cargo) will equal $p_{2}^{1}$, and the value of loss $c_{2}^{1}$. Also, to simplify the calculations, we take it equal to a constant value.

So, the event $E_{1}$ corresponds to the stage of arrival of the vehicle at the customs complex, that is, stage 1. Decomposition of this event allows us to distinguish two possible events in its structure: the presence of a queue of vehicles that arrived for service and the lack of free space in the warehouse. 
The event $E_{2}$ includes customs clearance of goods in the appropriate customs regime, its unloading and reception of quality and quantity, as well as preparation of goods for storage.

The event $E_{3}$ - includes goods storing in a temporary storage warehouse, picking and sending the order.

Existing determining methods for reliability levels in each link of the supply chain that are based on the principles of reliability, come out of the supply chain structure and the concept of "failure", the content of which can vary based on the specific conditions of the supply chain and the conditions that are presented to it.

\section{Conclusions}

The proposed methodology allows you to determine the level of reliability of each individual element in the process of placing goods in a temporary storage warehouse, located on the territory of the cargo customs complex. In the framework of the described algorithm for the analytical terms of reference creation, the method is substantially determined by the nature of the assigned management tasking, namely, the determination of unforeseen expenses from temporary delays in service or denial of service. Since the calculation of reliability indicators of the logistics chain is an important factor in the selection of forms and methods of their planning. Identification of threats to the stability of economic relations, the right choice of parameters for their assessment allows us to formulate a set of necessary measures to prevent failures in accordance with the possible costs that may be caused by these failures.

\section{Funding}

The authors received no direct funding for this research.

\section{Citation information}

Luzhanska, N. (2020). Impact of the cargo customs complex efficiency on the supply chain reliability. Journal of Sustainable Development of Transport and Logistics, 5(1), 96-102. doi:10.14254/jsdtl.2020.5-1.9

\section{References}

Biljan, J., \& Trajkov, A. (2012). Risk Management and customs performance improvements: the case of the Republic of Macedonia. Procedia - Social and Behavioral Sciences, 44, 301-313. doi.org/10.1016/j.sbspro.2012.05.033

Christopher, M. (2004). Logistika i upravlenie tsepochkami postavok (Logistics and Supply Chain Management). Saint Petersburg: Piter (in Russian).

Elliott, D., \& Bonsignori, C. (2019). The influence of customs capabilities and express delivery on trade $\begin{array}{llll}\text { flows. Journal of Air Transport } & \text { Management, 74, }\end{array}$ https://doi.org/10.1016/j.jairtraman.2018.09.007

Gadzhinskiy, A.M. (1999). Logistika (Logistics). Moscow: Marketing (in Russian).

Henningsson, S., \& Zinner Henriksen, H. (2011). Inscription of behaviour and flexible interpretation in Information Infrastructures: The case of European e-Customs. The Journal of Strategic Information Systems, 20(4), 355-372. https://doi.org/10.1016/j.jsis.2011.05.003

Jiang, B., Li, J., \& Shen, S. (2018). Supply chain risk assessment and control of port enterprises: Qingdao port as case study. The Asian Journal of Shipping and Logistics, 34(3), 198-208. https://doi.org/10.1016/j.ajsl.2018.09.003

Khendfild, R.B. \& Nikols, E.L. (Ed.). (2003). Reorganizatsia tsepei postavok. Sozdanie integrirovannykh sistem formirovaniia tsennostei (Reorganization of supply chains. Creation of integrated value formation systems). Moscow: Williams (in Russian).

Krikavsky, Ye.V. (2004). Do teorii optymizatsii logistychnykh vytrat (Towards the theory of logistics cost optimization). Sumy: SumSU (in Ukrainian). 
Mirotin, L.B. \& Sergeev, V.I. (Ed.). (2000). Osnovy logistiki (Logistics basics). Moscow: INFRA (in Russian).

Morales-Fusco, P., Sauri, S., Lekka, A.-M., \& Karousos, I. (2016). Assessing customs performance in the Mediterranean ports. KPI selection and best practices identification as part of the MEDNET $\begin{array}{llll}\text { Project. Transportation } \quad \text { Research } & \text { 374-383. }\end{array}$ https://doi.org/10.1016/j.trpro.2016.12.049

Pirttila, M., Virolainen, V.M., Lind, L., \& Karri T. (2020). Working capital management in the Russian automotive industry supply chain. International Journal of Production Economics, 221, 107474. https://doi.org/10.1016/j.ijpe. 2019.08.009

Pourakbar, M., \& Zuidwijk, R.A. (2018). The role of customs in securing containerized global supply chains. European Journal of Operational Research, 271(1), 331-340. https://doi.org/10.1016/j.ejor.2018.05.012

Pustynnikova, E.V. (2016). Integrirovannaia logistika (Integrated logistics). Ulyanovsk: USU (in Russian).

Raus, M., Flugge, B., \& Boutellier, R. (2009). Electronic customs innovation: An improvement of governmental infrastructures. Government Information Quarterly, 26(2), 246-256. https://doi.org/10.1016/j.giq.2008.11.008

Rodnikov, A.N. (2000). Logistika: terminologicheskij slovar (Logistics: terminological dictionary). Moscow: INFRA (in Russian).

Solano, A.B., Cedillo-Campos, M.G., \& Velarde Cantu, J.M. (2016). Reliability of the Supply Chain: Method of Self-Assessment as a First Step to Building Resilient System. International Journal of Combinatorial Optimization Problems and Informatics, 7(1), Jan-April 2016, 3-9. https://www.researchgate.net/publication/303381632_Reliability_of_the_Supply_Chain_Method_ of_Self-Assessment_as_a_First_Step_to_Building_Resilient_Systems

Stock, Dzh.P., \& Lambert, D.M. (Ed.). (2005). Strategicheskoe upravlenie logistikoi (Strategic Logistics Management). Moscow: INFRA-M (in Russian).

Urciuoli, L., Hintsa, J., \& Ahokas, J. (2013). Drivers and barriers affecting usage of e-Customs - A global survey with customs administrations using multivariate analysis techniques. Government Information Quarterly, 30(4), 473-485. https://doi.org/10.1016/j.giq.2013.06.001

Volpe Martincus, C., Carballo, J., \& Graziano, A. (2015). Customs. Journal of International Economics, 96(1), 119-137. https://doi.org/10.1016/j.jinteco.2015.01.011

Wang, Y., Jia, F., Schoenherr, T., Gong Y., \& Chen, L. (2019). Cross-border e-commerce firms as supply chain integrators: The management of three flows. Industrial Marketing Management. https://doi.org/10.1016/j.indmarman. 2019.09.004

Waters, D. (2003). Logistika: upravlenie tsepiu postavok (Logistics and Supply Chain Management). Moscow: UNITY (in Russian).

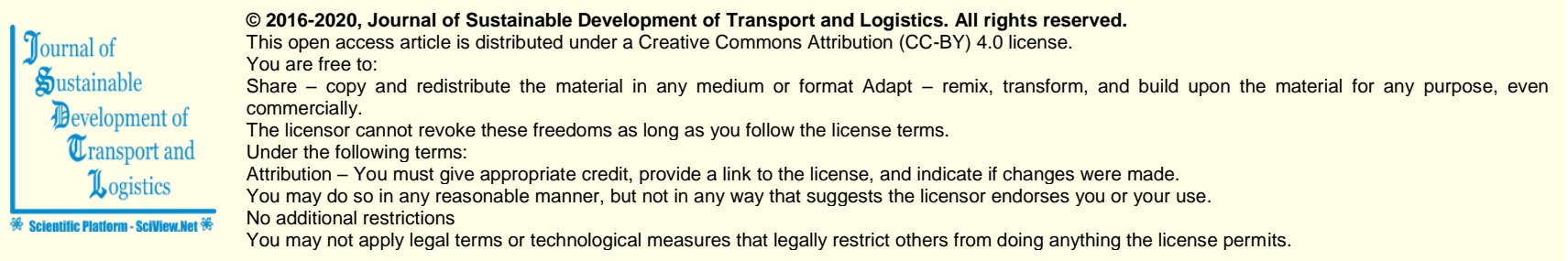

Journal of Sustainable Development of Transport and Logistics (ISSN: 2520-2979) is published by Scientific Publishing House "CSR", Poland, EU and Scientific Publishing House "SciView", Poland, EU

Publishing with JSDTL ensures:

- Immediate, universal access to your article on publication

- High visibility and discoverability via the JSDTL website

- Rapid publication

- Guaranteed legacy preservation of your article

- Discounts and waivers for authors in developing regions

Submit your manuscript to a JSDTL at https://jsdtl.sciview.net/ or submit.jsdtl@sciview.ne 